\title{
A Prospective, Single Center Study on Clinical Safety and Efficacy of Dinoprostone Gel for Cervical Ripening in Pregnant Women not in Labor
}

\author{
$\$$ \\ Julienne Katrina Beltran, $M D^{1}$ \\ Ramon M. Gonzalez, MD'
}

\section{ABSTRACT}

Objective To determine the safety of dinoprostone gel and clinical efficacy for cervical ripening among women for labor induction with a Bishop score of less than 9.

Methodology This is a prospective, single-center study where 165 women with a singleton pregnancy, cephalic presentation, at $\geq 36$ weeks $A O G$, candidates for labor induction, and with a Bishop score of less than 9 were subjected to cervical ripening using dinoprostone gel. The primary outcomes were induction success rate, spontaneous vaginal delivery rate, number of dinoprostone gels used and length of time to achieve induction success and deliver.

Results A median of 1 (range 1-3) dinoprostone gels were used per woman. The median intervals from labor induction to active labor and termination of pregnancy were 260 (range 0-2480) and 485 (range 0-2950) minutes, respectively. The median intervals from dinoprostone insertion to active labor and termination of pregnancy were 480 (range

Julienne Katrina Beltran jbb02389@gmail.com

1 Department of Obstetrics \& Gynecology,

University of Santo Tomas Hospital, Manila, Phillippines
60-2480) and 820 (range 134-3310) minutes, respectively. Labor was successfully induced in $83 \%$. No adverse events were noted. No significant differences based on parity were detected for the outcomes of dinoprostone dosage and mode of delivery, although in terms of relative proportion, more multiparous women gave birth normally $169 \%$ vs $57 \%, P=0.226)$. There was, however, evidence of increased induction success among women who have given birth previously $194 \%$ vs $79 \%$, P $=0.022$ ). The success group generally had higher Bishop scores (ie, success group had predominantly Bishop 4 and higher scores) and higher ages of gestation with more than $50 \%$ term patients. There was insufficient evidence to demonstrate a difference between the AOG groups. The duration from labor induction to the active phase of labor was shorter for those with BS $>4$ (median 240 minutes vs 265 minutes), while the duration from labor induction to termination of pregnancy was shorter for BS $\leq 4$ points (478 minutes vs 510 minutes). However, these were not statistically significant. Similarly, the duration from dinoprostone insertion to active phase of labor was shorter for those with BS $>4$ (median 420 minutes vs 502.5 minutes). The duration from dinoprostone insertion to termination of pregnancy 
was also shorter for BS $>4$ points 1685 minutes vs 835 minutes). However, these were not statistically significant. The median time from labor induction to active phase was 260 minutes $195 \% \mathrm{Cl} 210 \mathrm{~min}$ utes to 360 minutes). The median time from labor induction to termination was 490 minutes $195 \% \mathrm{Cl}$ 434 minutes to 590 minutes). None of the following were reported: tachysystole, nausea/vomiting, diarrhea, vaginal irritations, abdominal pain, back pain, headache, and dizziness.

Conclusion The use of dinoprostone gel is safe. No adverse events have been reported. Induction success was at $83.03 \%$. Vaginal delivery was achieved by $66.67 \%$ of the population. Significantly higher induction success and higher vaginal delivery rates were seen for the parous group.

\section{INTRODUCTION}

Cervical condition (cervical ripeness or favorability) is a good predictor of successful labor induction and subsequent vaginal delivery.[1-2, 10-11] However, early on there was no standard way of determining the "ripeness" or "favorability" of the cervix for labor induction. Therefore, in 1964, Dr. Edward $\mathrm{H}$. Bishop devised a cervical scoring system determining parous women that can be candidates for elective induction.[1,2] This cervical scoring system comprises cervical dilatation, effacement, as well as position, consistency, and station of the presenting part. $[1,2]$

Over time, this cervical scoring system became known as the Bishop Score.[2] It has since then evolved from merely selecting parous women candidates for elective induction to a scoring system that is used to select suitable candidates for labor induction. $[1,2]$ Through the years they have found out that induction may be safely and successfully performed in those with a Bishop score of 9 or more. [10] While for those with an unfavorable cervix (Bishop score $<6)$, there is an increased rate of cesarean delivery, [3] longer duration of induction, [6] increased risk of infection, [6] and uterine atony[7]. Neonatal risks encountered are increased with newborn intensive care unit admission and neonatal sepsis. [7]

Therefore, if the cervix is found to be unfavorable, cervical ripening (pharmacological or mechanical methods) preinduction is performed.[20-22] It is an intricate process that results in cervical softening and distensibility which eventually leads to cervical effacement and dilatation.[18] One method that is employed for cervical ripening is the administration of prostaglandins. [14]

For this study, the prostaglandin of choice is dinoprostone gel. It is a prostaglandin E2 analogue that is marketed as Primigyn. Primigyn is a $3 \mathrm{~mL}$ prefilled syringe of $0.5 \mathrm{mg}$ dinoprostone that is placed intracervically just below the internal cervical os [19]. After application, the patient must remain recumbent for at least 30 minutes [19]. It can be repeated every 6 hours for a maximum of 3 doses in a 24hour period if there are no or minimal changes in the cervix and minimal uterine activity after a given dose. There are no guidelines yet on when to exactly start labor induction using oxytocin but according to the manufacturer's guidelines, oxyłocin use may commence 6-12 hours after dinoprostone gel application. Caution must be exercised when using this in patients with ruptured membranes, glaucoma, asthma, pelvic infections, cardiac disease, renal impairment, hepatic impairment, and lung disease.[19] However, according to Towers, dinoprostone use was not associated with asthma worsening or exacerbation. [13] The most common side effect reported was uterine tachysystole, which is defined as more than five uterine contractions in a 10-minute period. [17] Because uterine tachysystole may be associated with fetal compromise, the use of dinoprostone gel in patients with pre-existing uterine contractions is not recommended. Other reported side effects are occasional nausea/vomiting, diarrhea, vaginal irritations, abdominal and back pain, headache, and dizziness.[17] Unfortunately, in cases when these adverse effects happen, irrigation of the gel preparation has not been shown to be effective.[17]

Most meta-analysis of dinoprostone reported the following after dinoprostone gel application. [14-16] There is a reduction in unfavorable/unchanged cervix after 12 to 24 hours (RR $0.41,95 \% \mathrm{Cl} 0.27$ 0.65 ; 6 trials, 567 women). There is a probable modest reduction in the rate of cesarean delivery (RR 0.91, 95\% Cl 0.81-1.02; 36 trials, 6599 women). There is a possibility of lower rate of failing to achieve vaginal delivery within 24 hours (RR 0.32, $95 \% \mathrm{Cl} 0.02-4.83 ; 2$ trials, 384 women).

Labor induction is the artificial stimulation of uterine contractions before the spontaneous onset of labor.[4] Roughly 5\% to $30 \%$ of pregnancy ends up 
in labor induction.[11] It is indicated when either the prevailing condition of the mother or the fetus outweighs the continuation of pregnancy. The more common indications reported in literature are PROM at term, oligohydramnios (amniotic fluid index less than $5 \mathrm{~cm}$ or single vertical pocket less than $2 \mathrm{~cm}$ ), IUGR, gestational diabetes mellitus (GDM) $\geq 40$ weeks, pre-eclampsia $\geq 37$ weeks and pregnancy at $\geq 41$ weeks AOG. $[4,5,8,9,10]$ Contraindications for labor induction are any condition that would hinder spontaneous labor or delivery. Maternal contraindications are placenta previa, previous classical CS, prior CS with an absolute contraindication, prior uterine surgery (eg, myomectomy), active genital herpes infection, and previous uterine rupture. $[4,10]$ Fetal contraindications are abnormal fetal lie or presentation, non-reassuring fetal heart rate pattern, severe hydrocephalus, and macrosomia $1>4000$ grams). $[4,10]$ Though benefits have been reported in literature (eg, decreased perinatal morbidity), still labor induction exposes patients to increased risk of failure if done with an unfavorable cervix, cesarean section, operative vaginal delivery, tachysystole, inadvertent delivery of the preterm infant if there was inaccurate dating of the pregnancy, uterine rupture, and chorioamnionitis with a prolonged labor induction in the setting of a ruptured membrane.[10]

Currently, there is no defined protocol for cervical ripening using dinoprostone gel. After a thorough search in databases (eg, Cochrane, Pubmed), there has yet to be any study regarding the clinical efficacy of dinoprostone gel for cervical ripening in terms of induction success rate and spontaneous vaginal delivery rate. Likewise, there was also no study seen regarding the dose-response rate of dinoprostone gel among women with a Bishop score <9. Therefore, this study aims to determine the safety of dinoprostone gel and its clinical efficacy for cervical ripening among women in labor with a Bishop score of $<9$. In particular, it aims to determine the clinical efficacy of dinoprostone gel for cervical ripening in terms of induction success rate and spontaneous vaginal delivery rate and the dose-response rate among women with a Bishop score $<9$.

\section{METHODOLOGY}

All women with a singleton pregnancy, cephalic in presentation at $\geq 36$ weeks $A O G$ candidate for labor induction with a Bishop score of less than 9 will be included in the study. Indications for induction are the following: 1) PROM with no signs of chorioamnionitis 2) gestational age of $\geq 41$ weeks 3) oligohydramnios 4) IUGR 5) overt or gestational diabetes mellitus at $\geq 40$ weeks $A O G$ 6) hypertension in pregnancy at $\geq 37$ weeks $A O G$.

Recruitment will start once the patient is diagnosed to have any of the indications for induction of labor. This will be done by the principal investigator herself.

On admission, after the principal investigator does a thorough and comprehensive explanation regarding cervical ripening using dinoprostone gel, labor induction and the study, informed consent will be collected for it, respectively. An admitting internal examination (IE) will be done by the principal investigator and a third-year OB-GYN resident and the Bishop score will be determined afterwards, likewise by the principal investigator and the third year OB-GYN resident and both will be recorded. Prior to cervical ripening, a non-stress test will be performed. Once fetal distress is ruled out, cervical ripening using dinoprostone gel will be done. Dinoprostone gel (Primigyn) comes in a disposable syringe with $3 \mathrm{~g}$ of translucent gel containing $0.5 \mathrm{mg}$ dinoprostone. The syringe consists of: 1) catheter, 2) plunger, and 3) barrel. When packed, the plunger is attached to the nozzle of the barrel. Screw on the catheter, which is packed separately on to the nozzle. Insert the catheter into the endocervix and then push the plunger to expel the entire gel $13 \mathrm{~g}$ gel containing $0.5 \mathrm{mg}$ dinoprostone) through the catheter.[20] The dose can be repeated in 6 to 12 hours if there is no or minimal cervical change and uterine activity is minimal following the first dose. This is following the manufacturer's recommendation; dinoprostone gel may be repeated every 6 to 12 hours for a maximum of 3 doses within a 24-hour period.[21]

Because of the potential for uterine tachysystole with concurrent use of oxytocin and prostaglandin administration, the time interval between the final dose and initiation of oxytocin should be 6 to 12 hours.[20-21] Therefore, 6 hours after dinoprostone gel application, labor induction using oxytocin will commence. Oxyłocin will be given initially at $2 \mathrm{mU} /$ minute and increased every 15 minutes over 2 hours to $30 \mathrm{mU} /$ minute or until regular painful uterine contractions are confirmed or labor has progressed or 
contractions are at least 200 Montevideo units. Electronic fetal monitoring will be done during the entire labor induction. Labor induction will be pursued for a minimum of 12 hours unless any of the following occurs: 1) any sign of fetal distress (eg, persistent decelerations and bradycardia) 2) presence of clinical signs and symptoms of chorioamnionitis (intrapartum temperature of at least $380 \mathrm{C}$ and at least one of the following present: uterine tenderness, foul smelling vaginal discharge or amniotic fluid or maternal or fetal tachycardia and/or biochemical signs of infection - C-reactive protein (CRP) at $>13.03$ or white blood cell count at $>12.8$ and segmenters in $\%$ at $>0.85$ )[12] 3) arrest in cervical dilatation (during the active phase of labor, no change in cervical dilatation for more than 2 hours) 4) arrest in descent (during the pelvic division, $\geq 8 \mathrm{~cm}$, no change in the station for more than 1 hour) and 5) failure in descent (no descent in deceleration phase or second stage). If the fetal heart rate pattern is reassuring (baseline fetal heart rate at $110-160 \mathrm{bpm}$, with moderate variability and accelerations and no decelerations), cesarean delivery prior to the active phase of labor will not be permitted unless the patient has undergone a minimum of 12 hours of labor induction using oxytocin. This will be determined by the senior resident on duty (resident who is in their last year of OB-GYN residency training).

The patient will be followed through for the entire labor induction. In the event that there is rupture of membranes during the labor induction, 6 hours from rupture of membranes and labor induction is still ongoing, a baseline complete blood count and CRP examination will be done. Also, ampicillin $2 \mathrm{~g} / \mathrm{IV}$ after a negative skin test will be given at that time as well. Complete blood count and CRP determination and giving of ampicillin $2 \mathrm{~g} / \mathrm{IV}$ every 6 hours will be done thereafter until there is spontaneous vaginal delivery or termination of labor induction because of the occurrence of the aforementioned events.

All women with a singleton pregnancy, cephalic in presentation at $\geq 36$ weeks AOG candidate for labor induction with a Bishop score of less than 9 will be included in the study. Indications for induction are the following: 1) PROM with no signs of chorioamnionitis 2) gestational age of $\geq 41$ weeks 3) oligohydramnios 4) IUGR 5) overt or gestational diabetes mellitus at $\geq 40$ weeks AOG 6) hypertension in pregnancy at $\geq 37$ weeks AOG

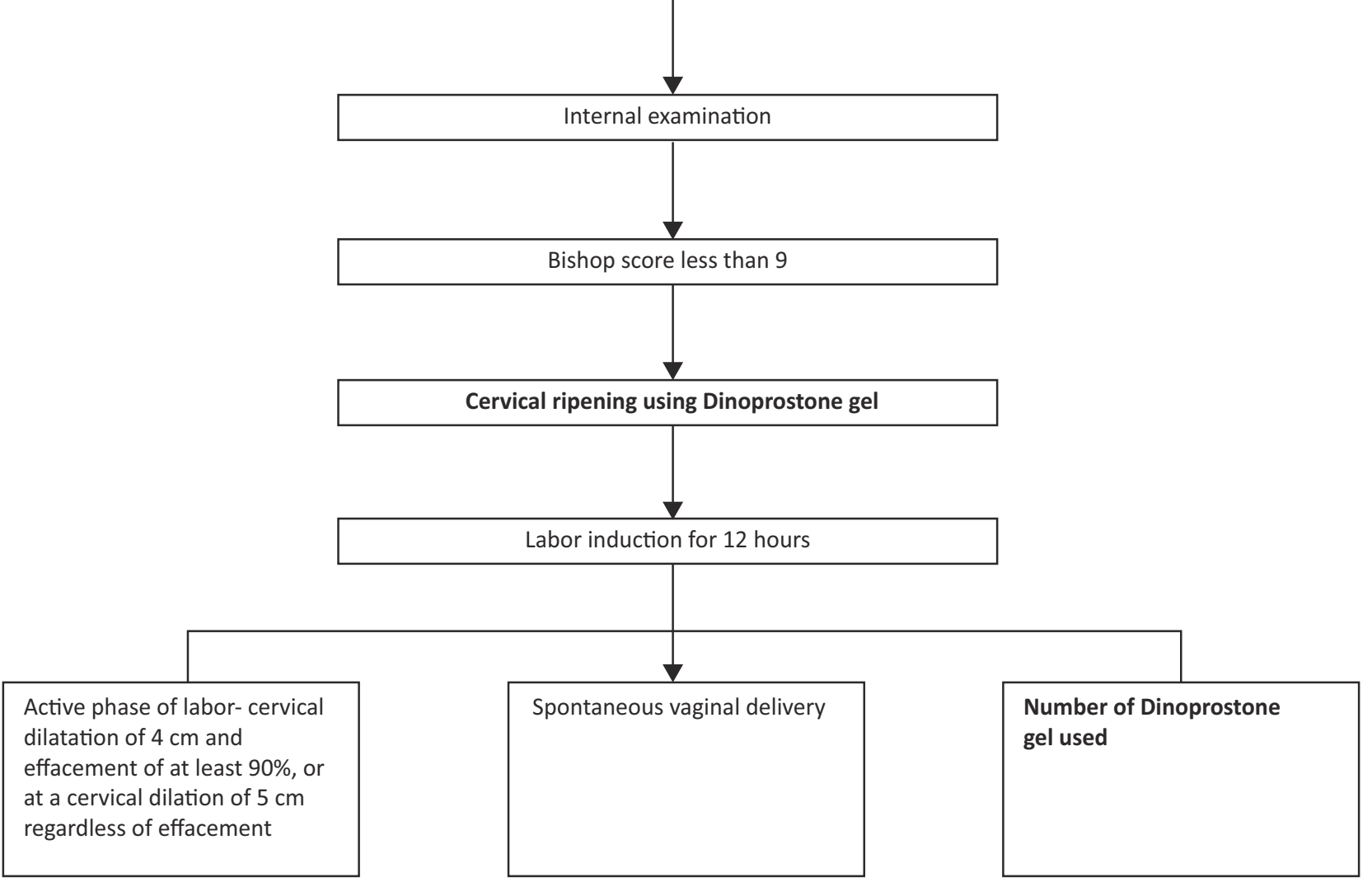

Fig. 1. Sampling and Methodology Framework for This Study 


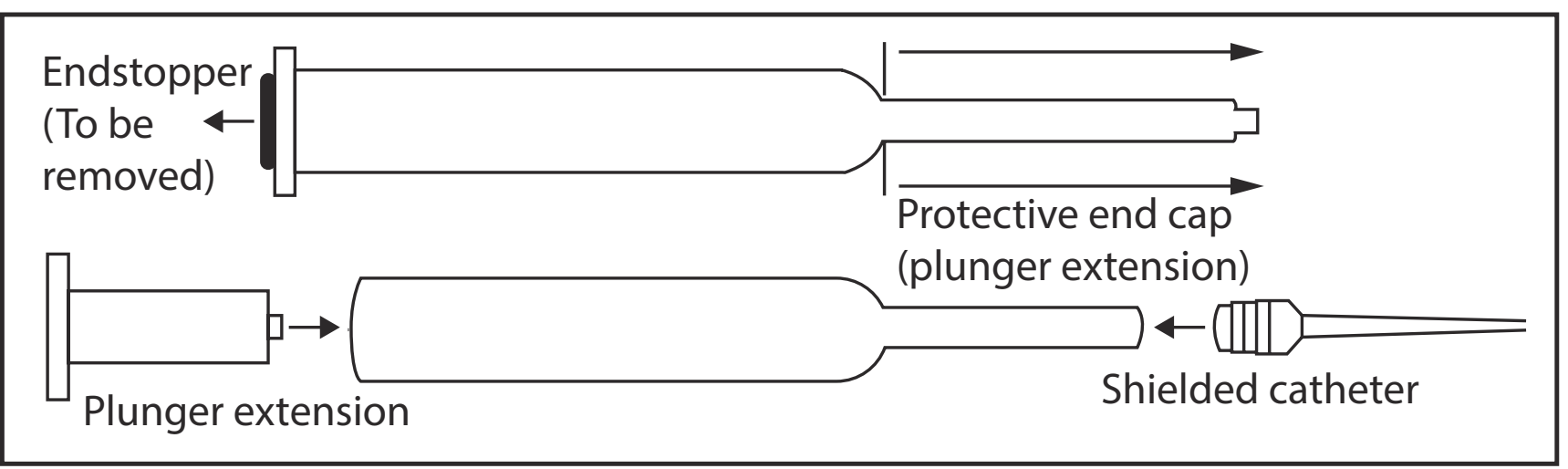

Figure 2. Dinoprostone gel disposable syringe

The major outcome measurement is reaching the active phase of labor.[7] Active phase of labor is defined as cervical dilatation of $4 \mathrm{~cm}$ and effacement of at least $90 \%$, or at a cervical dilation of $5 \mathrm{~cm}$ regardless of effacement.[6-7] The other outcomes are spontaneous vaginal delivery rate and dose-response rate of dinoprostone gel among women with Bishop score <9. Throughout the labor induction, participants will be monitored vigilantly in order to detect immediately any adverse events. In so doing, timely interventions may be given. In case of any adverse events not mentioned on paragraph 3 of the rationale and background of the study part of this paper, the principal investigator will shoulder the expenses for the necessary interventions.

Participation in the study will end once the patient has delivered whether by normal spontaneous delivery or cesarean section. No follow-up is necessary after the delivery of the baby.

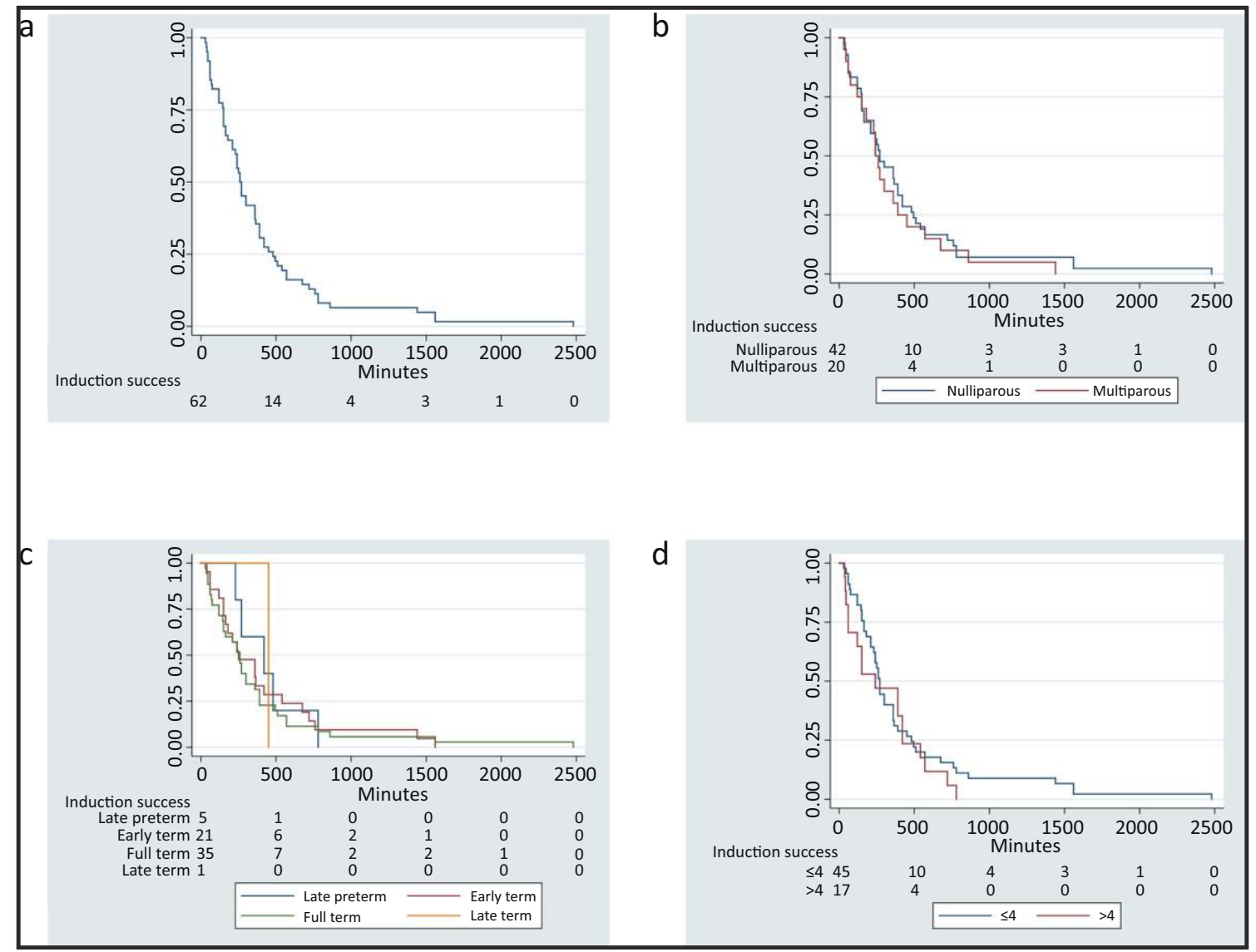

Figure 3. Time to induction success: a. overall; b. by parity; c. by age of gestation; $d$. by Bishop Score. The X-axis pertains to minutes from labor induction to active phase. The Y-axis pertains to probability of induction success. 


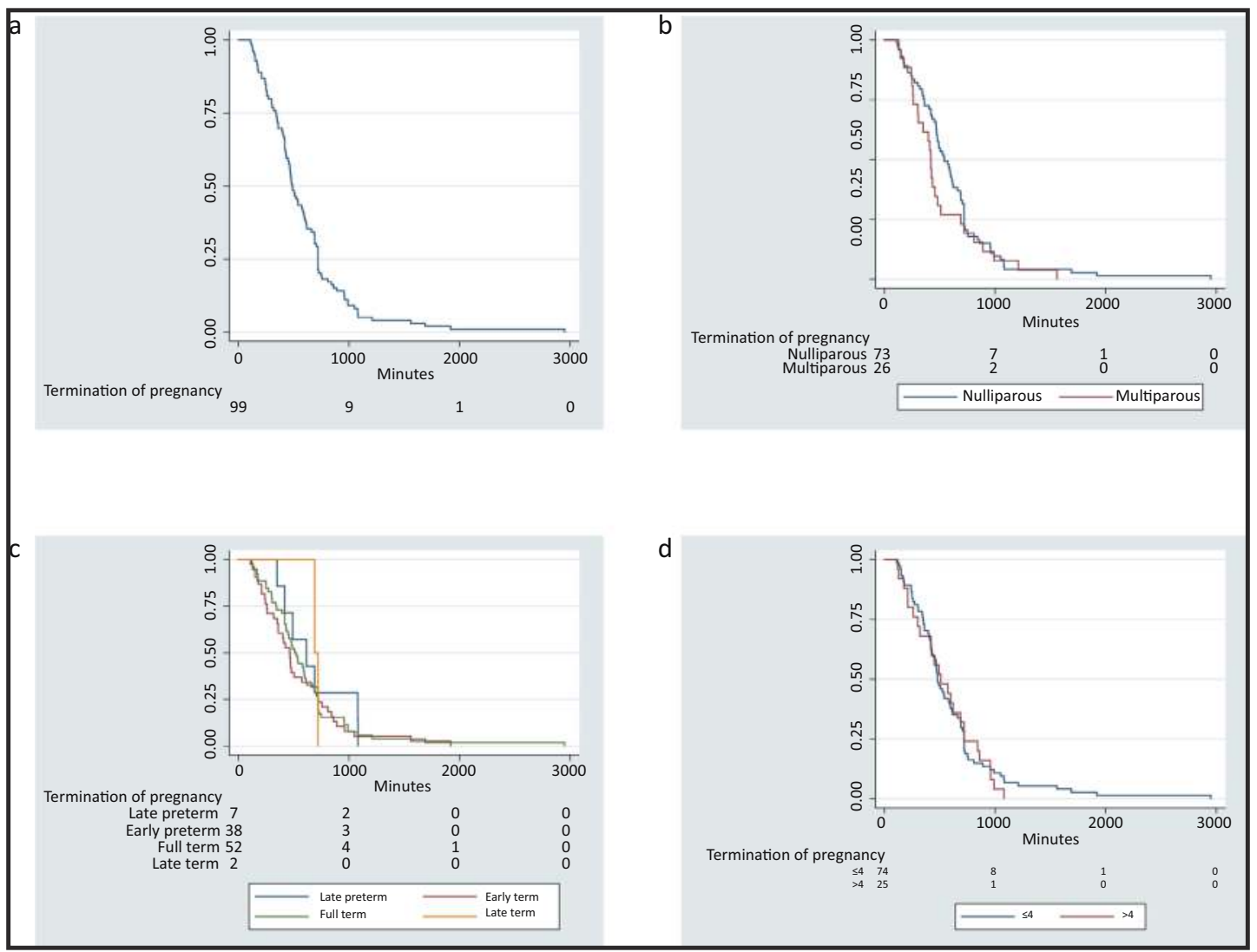

Figure 4. Time to termination of pregnancy: a. overall; b. by parity; c. by age of gestation; d. by Bishop Score. The X-axis pertains to minutes from labor induction to termination of pregnancy. The Y-axis pertains to probability of termination of pregnancy.

\section{RESULTS}

A total of 165 pregnant women were included in the analysis with a mean age of $29 \pm 6$ years, mostly primigravid $(64 \%)$ and nulliparous $(71 \%)$, and at a median 39 weeks (range 34-41) of gestation. Six in 10 of these gave birth via spontaneous vaginal delivery; a third underwent cesarean operation, while $7 \%$ delivered vaginally aided by instrumentation (Table 3).

A median of 1 (range 1-3) dinoprostone gels were used per woman. The median intervals from labor induction to active labor and termination of pregnancy were 260 (range 0-2480) and 485 (range 0-2950) minutes, respectively. The median intervals from dinoprostone insertion to active labor and termination of pregnancy were 480 (range 60-2480) and 820 (range 134-3310) minutes, respectively. Labor was successfully induced in $83 \%$. No adverse events were noted in the study (Table 4).

No significant differences based on parity were detected for the outcomes of dinoprostone dosage and mode of delivery, although in terms of relative proportion, more multiparous women gave birth normally $(69 \%$ vs $57 \%, P=0.226)$. There was, howev- er, evidence of increased induction success among women who have given birth previously $194 \%$ vs $79 \%, P=0.022$ ) (Table 4.1).

The success group generally had higher Bishop scores (ie, success group had predominantly Bishop 4 and higher scores) and higher ages of gestation, more than $50 \%$ term patients (Table 4.2 ).

We compared duration from labor induction or dinoprostone insertion to active phase of labor or termination of pregnancy across ages of gestation. However, we had insufficient evidence to demonstrate a difference between the AOG groups (Table 4.3).

We compared patients with Bishop scores $\leq 4$ versus the above four points. In both groups, the median number of dinoprostone gel was one dose. The duration from labor induction to active phase of labor was shorter for those with BS >4 (median 240 minutes vs 265 minutes), while the duration from labor induction to termination of pregnancy was shorter for $\mathrm{BS} \leq 4$ points (478 minutes vs 510 minutes). However, these were not statistically significant.

Similarly, the duration from dinoprostone insertion to active phase of labor was shorter for those with BS >4 (median 420 minutes vs 502.5 minutes). The 
duration from dinoprostone insertion to termination of pregnancy was also shorter for BS $>4$ points $(685$ minutes vs 835 minutes). However, these were not statistically significant.

The median time from labor induction to active phase was 260 minutes $195 \% \mathrm{Cl} 210$ minutes to 360 minutes). Disaggregations for parity, AOG, and Bishop scores are given in Table 5 and Figure 3.
The median time from labor induction to termination was 490 minutes ( $95 \% \mathrm{Cl} 434$ to 590 minutes). Disaggregations for parity, AOG, and Bishop scores are given in Table 6 and Figure 4.

\section{Adverse events}

None of the following were reported: tachysystole, nausea/vomiting, diarrhea, vaginal irritations, abdominal pain, back pain, headache, dizziness.

Table 1. Bishop Score to Assess Cervical Favorability in Women for Labor Induction

\begin{tabular}{lcccc}
\hline Cervix & Score & & & \\
\hline \\
Dilatation & $\mathbf{0}$ & $\mathbf{1}$ & $\mathbf{2}$ & $\mathbf{3}$ \\
Effacement & Closed & $1-2$ & $3-4$ & $>5 \mathrm{~cm}$ \\
Station & $0-30 \%$ & $40-50 \%$ & $60-70 \%$ & $>80 \%$ \\
Position & -3 & -2 & -1 & 0 to +1 \\
Consistency & Posterior & Midposition & Anterior & - \\
\hline
\end{tabular}

Table 2. Prostaglandins for Preinduction Cervical Ripening in the Market

\begin{tabular}{|c|c|c|}
\hline Prostaglandin & Agent & Route/Dose \\
\hline Prostaglandin E 1 & Misoprostol (Cytotec) 100 or 200 pg tablet & $\begin{array}{l}\text { Vaginal, } 25 \mu g \text {; repeat every } 3-6 \text { hrs prn } \\
\text { Oral, } 50-100 \mu \text {; repeat every } 3-6 \text { hrs, prn }\end{array}$ \\
\hline \multirow[t]{2}{*}{ Prostaglandin E2 } & Dinoprostone gel (Primigyn) 0.5 mg & $\begin{array}{l}\text { Intracervical, } 0.5 \mathrm{mg} \text {, every } 6 \text { hours, total of } 3 \text { doses } \\
\text { for } 24 \text { hours }\end{array}$ \\
\hline & Dinoprostone vaginal insert (Propess) $10 \mathrm{mg}$ & Posterior fornix, $10 \mathrm{mg}$ \\
\hline
\end{tabular}

Table 3. Demographic characteristics, indications for labor induction and type of delivery in 165 pregnant women who underwent labor induction

Mean \pm SD; Frequency (\%); Median (Range)

\begin{tabular}{lc}
\hline Age, years & $28.78 \pm 5.63$ \\
Gravidity & $106(64.24)$ \\
Primigravida & $59(35.76)$ \\
Multigravida & \\
Parity & $117(70.91)$ \\
Nulliparous & $48(29.09)$ \\
Parous & $39(34-41)$ \\
Age of gestation & $1(0.61)$ \\
34 & $1(0.61)$ \\
35 & $7(4.24)$ \\
36 & $18(10.91)$ \\
37 & $48(29.09)$ \\
38 & $52(31.52)$ \\
39 & $33(20)$ \\
40 & $5(3.03)$ \\
41 &
\end{tabular}


(Table 3 continued)

Mean \pm SD; Frequency (\%); Median (Range)

Type of delivery

Normal spontaneous delivery

C - section

Operative vaginal delivery

$12(7.27)$

Indication for labor induction

PROM with no signs of chorioamnionitis

$68(41.21)$

Gestational age of $\geq 41$ weeks

Overt or gestational DM at $\geq 40$ weeks

Oligohydramnios

Hypertensive disorders at $\geq 37$ weeks AOG

19 (1 1.52$)$

IUGR

$1(0.61)$

Table 4.0. Clinical outcomes for dinoprostone gel use in 165 pregnant women who underwent cervical ripening prior to labor induction

\section{Frequency (\%); Median range}

Number of dinoprostone gel used

$$
1(1-3)
$$

Duration from start of labor induction to active phase of labor,

$260(0-2480)$ $\min [\mathrm{n}=63]$

Duration from start of labor induction to termination of preg-

$485(0-2950)$

nancy, $\min [\mathrm{n}=100]$

$480(60-2840)$ $\min [n=138]$

Duration from Dinoprostone insertion to termination of pregnancy, $\min [\mathrm{n}=166]$

$820(134-3310)$

Induction success

$137(83.03)$

Vaginal delivery 24 hours $[\mathrm{n}=100]$

$57(57)$

(labor induction to termination of pregnancy)

Table 4.1. Clinical outcomes based on parity in 165 pregnant women who underwent cervical ripening prior to labor induction

\begin{tabular}{lccc}
\hline & $\begin{array}{c}\text { Nulliparous } \\
\mathbf{n = 1 1 7}\end{array}$ & $\begin{array}{c}\text { Parous } \\
\mathbf{n = 4 8}\end{array}$ & p-value \\
\cline { 2 - 3 } & \multicolumn{1}{c}{ Frequency (\%) } & $0.733^{*}$ \\
\hline Number of dinoprostone gel used & $1(1-3)$ & $1(1-3)$ & $0.295 \dagger$ \\
Spontaneous vaginal delivery & $66(56.41)$ & $32(66.67)$ & $0.021 \dagger$ \\
Induction success & $92(78.63)$ & $45(93.75)$ & $0.001 \dagger$ \\
$\begin{array}{l}\text { Vaginal delivery 24 hours [n=100] } \\
\text { (labor induction to termination of }\end{array}$ & $34(46.58)$ & $23(85.19)$ & \\
pregnancy) & & & \\
\hline
\end{tabular}

Statistical test used: *- Wilcoxon's rank sum test; $\dagger$ - Fisher's exact test 
Table 4.2. Success of induction and vaginal delivery within 24 hours of labor induction across Bishop scores and $A O G$ in 165 pregnant women who underwent cervical ripening prior to labor induction

\begin{tabular}{|c|c|c|c|}
\hline & $\begin{array}{l}\text { Success } \\
n=137\end{array}$ & $\begin{array}{l}\text { Failure } \\
n=28\end{array}$ & \multirow[t]{2}{*}{ p-value } \\
\hline \multicolumn{3}{|c|}{ Frequency (\%); Median (Range) } & \\
\hline Bishop score & $4(2-7)$ & $4(2-6)$ & $0.04^{*}$ \\
\hline 2 & 11 (8.03) & 4 (14.29) & $0.352 \dagger$ \\
\hline 3 & 23 (16.79) & $9(32.14)$ & \\
\hline 4 & $64(46.72)$ & $10(35.71)$ & \\
\hline 5 & $24(17.52)$ & $3(10.71)$ & \\
\hline 6 & 11 (8.03) & $2(7.14)$ & \\
\hline 7 & $4(2.92)$ & $0(0)$ & \\
\hline AOG & $39(35-41)$ & $38(34-41)$ & $0.024^{*}$ \\
\hline Late preterm & $7(5.11)$ & $2(7.14)$ & $0.214 \dagger$ \\
\hline Early term & $51(37.23)$ & 15 (53.57) & \\
\hline Full term & 75 (54.74) & 10 (35.71) & \\
\hline Late term & $4(2.92)$ & $1(3.57)$ & \\
\hline $\begin{array}{l}\text { Vaginal delivery } 24 \text { hours } \\
{[n=100]} \\
\text { (labor induction to termina- } \\
\text { tion of pregnancy) }\end{array}$ & $57(73.08)$ & 0 & $<0.001 \dagger$ \\
\hline
\end{tabular}

Table 4.3. Clinical outcomes based on AOG in 165 pregnant women who underwent cervical ripening prior to labor induction

\begin{tabular}{|c|c|c|c|c|c|}
\hline & $\begin{array}{l}\text { Late preterm } \\
\qquad(\mathrm{n}=9)\end{array}$ & $\begin{array}{l}\text { Early term } \\
\qquad(n=66)\end{array}$ & $\begin{array}{c}\text { Full term } \\
(\mathrm{n}=85)\end{array}$ & $\begin{array}{l}\text { Late term } \\
\qquad(n=5)\end{array}$ & p-value \\
\hline \multicolumn{6}{|c|}{ Median (Range) } \\
\hline $\begin{array}{l}\text { Number of dinoprostone } \\
\text { gel used }\end{array}$ & $1(1-1)$ & $1(1-3)$ & $1(1-3)$ & $1(1-2)$ & $0.311 \S$ \\
\hline $\begin{array}{l}\text { Duration from start of } \\
\text { labor induction to active } \\
\text { phase of labor, min } \\
{[n=63]}\end{array}$ & $420(230-780)$ & $250(40-1560)$ & $250(0-2480)$ & $450(450-450)$ & $0.378 \S$ \\
\hline $\begin{array}{l}\text { Duration from start of } \\
\text { labor induction to termi- } \\
\text { nation of pregnancy, min } \\
{[n=100]}\end{array}$ & $\begin{array}{l}616(349 \\
-1082)\end{array}$ & $\begin{array}{l}465.5(110 \\
-1920)\end{array}$ & $510(0-2950)$ & 705 (690 - 720) & $0.418 \S$ \\
\hline $\begin{array}{l}\text { Duration from Dinopros- } \\
\text { tone insertion to active } \\
\text { phase of labor, min } \\
{[n=138]}\end{array}$ & $\begin{array}{l}690(360 \\
-1920)\end{array}$ & $420(90-2520)$ & $510(60-2840)$ & $600(240-915)$ & $0.523 \S$ \\
\hline $\begin{array}{l}\text { Duration from Dinopros- } \\
\text { tone insertion to termina- } \\
\text { tion of pregnancy, min } \\
{[n=166]}\end{array}$ & $\begin{array}{l}975(414 \\
-2222)\end{array}$ & $\begin{array}{l}652.5(134 \\
-2640)\end{array}$ & $\begin{array}{l}835(163 \\
-3310)\end{array}$ & $\begin{array}{l}1050(270 \\
-1800)\end{array}$ & $0.191 \S$ \\
\hline $\begin{array}{l}\text { Vaginal delivery } 24 \text { hours } \\
{[\mathrm{n}=100]} \\
\text { (labor induction to termi- } \\
\text { nation of pregnancy) }\end{array}$ & $4(57.14)$ & $21(55.26)$ & 31 (58.49) & $1(50)$ & $0.975 \dagger$ \\
\hline
\end{tabular}


Table 4.4. Clinical outcomes based on Bishop score in 165 pregnant women who underwent cervical ripening prior to labor induction

\begin{tabular}{|c|c|c|c|}
\hline & $\leq 4$ & $>4$ & p-value \\
\hline \multicolumn{4}{|c|}{ Median (Range) } \\
\hline Number of dinoprostone gel used & $1(1-3)$ & $1(1-2)$ & $0.116^{*}$ \\
\hline $\begin{array}{l}\text { Duration from start of labor induction to active } \\
\text { phase of labor, } \min [n=63]\end{array}$ & $265(0-2480)$ & $240(36-780)$ & 0.51 * \\
\hline $\begin{array}{l}\text { Duration from start of labor induction to termination } \\
\text { of pregnancy, } \min [n=100]\end{array}$ & $478(0-2950)$ & $510(120-1080)$ & $0.965^{*}$ \\
\hline $\begin{array}{l}\text { Duration from Dinoprostone insertion to active } \\
\text { phase of labor, } \min [n=138]\end{array}$ & $502.5(60-2840)$ & $420(60-1320)$ & 0.493 * \\
\hline $\begin{array}{l}\text { Duration from Dinoprostone insertion to termination } \\
\text { of pregnancy, } \min [n=166]\end{array}$ & 835 (134 - 3310$)$ & $685(195-1802)$ & $0.176 *$ \\
\hline $\begin{array}{l}\text { Vaginal delivery } 24 \text { hours } \\
\text { (labor induction to termination of pregnancy) }\end{array}$ & $42(56)$ & $15(60)$ & $0.818 \ddagger$ \\
\hline
\end{tabular}

Statistical test used: *- Wilcoxon’s rank sum test; $†$ - Fisher's exact test ; $\neq$ - Chi squared test

Table 5. Time to achieve phase of labor from labor induction in minutes in 165 pregnant women who underwent cervical ripening prior to labor induction

\begin{tabular}{lc}
\hline & Median time in minutes (95\% CI) \\
\hline Overall & $260(210-360)$ \\
Parity & $270(165-390)$ \\
Multiparous & $240(120-390)$ \\
AOG & \\
Late preterm & $420(230-780)$ \\
Early term & $250(150-420)$ \\
Full term & $260(150-300)$ \\
Late term & - \\
Bishop score & \\
$\leq 4$ & $270(210-360)$ \\
$>4$ & $240(60-420)$ \\
\hline
\end{tabular}

Table 6. Time to achieve pregnancy termination from labor induction in minutes in 165 pregnant women who underwent cervical ripening prior to labor induction

\begin{tabular}{lc}
\hline \multicolumn{1}{l}{ Overall } & Median time in minutes (95\% CI) \\
Parity & $490(434-590)$ \\
Nulliparous & $540(470-620)$ \\
Multiparous & $419(302-480)$ \\
AOG & \\
Late preterm & $616(349-1080)$ \\
Early term & $465(353-574)$ \\
Full term & $510(430-600)$ \\
Late term & $690(690-)$. \\
Bishop score & \\
$\leq 4$ & $478(430-595)$ \\
$>4$ & $510(320-720)$ \\
\hline
\end{tabular}




\section{DISCUSSION}

Labor induction comprises $20 \%$ of all births. It has gradually increased through the decades due to a variety of reasons and one of this is the availability of myriads of cervical ripening agents in the market. This study focuses on the cervical ripening agent, dinoprostone gel, a prostaglandin E2 analogue. $[14,19]$

This study aims to determine the safety of dinoprostone gel and its clinical efficacy for cervical ripening among women in labor with a Bishop score of $<9$. In particular, it aims to determine the clinical efficacy of dinoprostone gel for cervical ripening in terms of induction success rate and spontaneous vaginal delivery rate and the dose-response rate among women with Bishop score $<9$.

Labor was successfully induced in $83.03 \%$ and vaginal delivery was achieved in $66.67 \%$ with the use of dinoprostone gel as a cervical ripening agent. This was higher in multiparous women, increasing age of gestation, and higher Bishop score. No adverse events were reported. The median intervals from labor induction to active labor and termination of pregnancy were 260 (4.3 hours) (range 0-2480) minutes and 485 (8.08 hours) (range 0-2950) minutes, respectively. Ninetynine percent of those who had vaginal delivery delivered within 24 hours.

Our findings are consistent with the studies done by Alfirevic, Hawkins, Kelly, and Boulvain, which showed that dinoprostone gel increases the probability of having successful labor induction, having a vaginal delivery and lower rate of failing to achieve a vaginal delivery within 24 hours.[14-16,23] This is due to the fact that application of dinoprostone gel results in cervical softening and distensibility, which eventually leads to a more favourable response to oxytocin when it is given during labor induction. $[14,18]$

Our findings showed a faster induction to delivery time compared with a study done by Mahendru 8.08 hours vs 11.6 hours), but a lower vaginal delivery rate $(66.57 \%$ vs $91.1 \%)$. [24] However, this study has a smaller population and included only primigravids. Furthermore, our findings showed better outcomes in terms of vaginal delivery achieved within 24 hours $(99 \%$ vs $79 \%$ ) stated in another study. [23]

Our study has significant clinical implications for obstetrics. Labor induction has become one of the most common procedures given to pregnant women. Dinoprostone gel use prior to oxytocin has led to higher induction success rate and vaginal delivery, which translates to fewer hours spent in labor, thus fewer hours spent in the delivery room. Therefore, fewer money spent on delivery room usage and eventually fewer money spent on delivery because vaginal delivery is significantly less costly than a cesarean delivery. This shorter time spent in labor does not only have financial impact but clinical impact as well, since prolonged labor and cesarean delivery are associated with known maternal and neonatal morbidities. With this in mind, we recommend the use of dinoprostone gel prior to labor induction for all women to increase the success of labor induction and vaginal delivery and because of its safety profile.

Strengths of this study include that it was done at the University of Santo Tomas Hospital only, which decreases the differences in labor induction protocol. Only the principal author did the baseline internal examination findings in determining the Bishop score, therefore, decreasing inter-observer variability and there were few exclusion criteria which increases the results generalizing ability.

Limitations of the study are the following: the study was a single arm trial and therefore no randomization or blinding was done. Dose-response rate could not be determined because patients were not randomized to receive 1, 2, and 3 doses. They received another dose if they needed it. Therefore, the results seemed counterintuitive where those who received a single dose had better outcomes than those who received 2-3 doses.

For future studies, we recommend comparing dinoprostone gel with another agent that is commonly used as a cervical priming agent in the Philippines or with a novelty method. Also, there should be a larger population to increase the power of the study. Lastly, future studies should look into the maternal and neonatal outcomes of patients who had dinoprostone gel prior to labor induction to have more clinical impact to obstetrics and pediatrics as well.

\section{CONCLUSION}

Based on this present single center prospective study, dinoprostone gel is a safe cervical ripening agent. Dinoprostone gel followed by oxytocin achieved $83.03 \%$ induction success rate and $66.67 \%$ vaginal delivery rate. Significantly higher rate of induction success and vaginal delivery was achieved for the multiparous group, increasing $A O G$ and also a higher Bishop score. 


\section{REFERENCES}

1. Bishop EH. Pelvic Scoring for Elective Induction. Obstetrics \& Gynecology. 1964;24:266-8.

2. Danielsen C, Hunter G, Older M, Davis G. Using Bishop Score to Predict Labor Induction Time and Failure Rate. 2008;

3. Clark SL, Miller DD, Belfort MA, Dildy GA, Frye DK, Meyers JA. Neonatal and maternal outcomes associated with elective term delivery. American Journal of Obstetrics and Gynecology. 2009 Feb 1;200(2):156-e 1.

4. Cunningham F, Leveno K, Bloom S, Spong CY, Dashe J. Williams Obstetrics, 24e. McGraw-Hill; 2014.

5. Gülmezoglu AM, Crowther CA, Middleton P, Heatley E. Induction of labour for improving birth outcomes for women at or beyond term. Cochrane Database of Systematic Reviews. 2012(6).

6. Rouse DJ, Owen J, Hauth JC. Criteria for failed labor induction: prospective evaluation of a standardized protocol. Obstetrics \& Gynecology. 2000 Nov 1;96(5):671-7.

7. Rouse DJ, Weiner SJ, Bloom SL, Varner MW, Spong CY, Ramin SM, et al. Failed labor induction: toward an objective diagnosis. Obstetrics and Gynecology. 2011 Feb; $117(201): 267$.

8. Caughey $A B$, Sundaram V, Kaimal AJ, Gienger A, Cheng YW, McDonald KM, et al. Systematic review: elective induction of labor versus expectant management of pregnancy. Annals of Internal Medicine. 2009 Aug 18;151 (4):252-63.

9. Mozurkewich E, Chilimigras J, Koepke E, Keeton K, King VJ. Indications for induction of labour: a best-evidence review. BJOG: An International Journal of Obstetrics \& Gynaecology. 2009 Apr;1 16(5):626-36.

10. Leduc D, Biringer A, Lee L, Dy J, Corbett T, Duperron L, et al. Induction of labour. Journal of Obstetrics and Gynaecology Canada. 2013 Sep 1;35(9):840-57.

11. Bueno B, San-Frutos L, Perez-Medina T, Barbancho C, Troyano J, Bajo J. The labor induction: integrated clinical and sonographic variables that predict the outcome. Journal of Perinatology. 2007 Jan;27(1):4.

12. Magpoc-Mendoza J, Gonzalez, R. Accuracy of white blood cell count and $C$ reactive protein determination in predicting chorioamnionitis in pregnant women with rupture of membranes. University of Santo Tomas Hospital.

13. Towers CV, Briggs GG, Rojas JA. The use of prostaglandin E2 in pregnant patients with asthma. American Journal of Obstetrics and Gynecology. 2004 Jun 1; 190(6): 1777-80.

14. Hawkins JS, Wing DA. Current pharmacotherapy options for labor induction. Expert Opinion on Pharmacotherapy. 2012 Oct 1;13(14):2005-14.

15. Kelly AJ, Alfirevic Z, Ghosh A. Outpatient versus inpatient induction of labour for improving birth outcomes. Cochrane Database of Systematic Reviews. 2013(11).
16. Boulvain $M$, Kelly $\mathrm{A}$, Irion $\mathrm{O}$. Intracervical prostaglandins for induction of labour. Cochrane Database of Systematic Reviews. 2008(1).

17. Macones $G$. Intrapartum fetal heart rate monitoring: nomenclature, interpretation, and general management principles. Obstetrics and Gynecology. 2009 Jul 1;114(1):192-202.

18. Word RA, Li XH, Hnat M, Carrick K. Dynamics of cervical remodeling during pregnancy and parturition: mechanisms and current concepts. In Seminars in Reproductive Medicine. 2007 Jan 25(1):69-79. Thieme Publishers, Inc., 333 Seventh Avenue, New York, NY 10001, USA..

19. Serums B. Vaccines Limited. Chorionic Gonadotrophin (HuCoG®) Product Leaflet. Revised date: January 2013.

20. Sharma P, Sharma S, Shergill H. Comparative evaluation of low dose-vaginal misoprostol and intra-cervical dinoprostone for cervical ripening and induction of labour in term pregnancy. International Journal of Reproduction, Contraception, Obstetricsafterwardand Gynecology. 2016;5(12):

21. Cengiz H, Yalvac S, Yavuzcan A, Kandemır O. Prediction of successful induction of labour with dinoprostone in a homogeneous group of patients. South African Journal of Obstetrics and Gynaecology. 2012;18(1).

22. Khan I, Sarker SJ, Hackshaw A. Smaller sample sizes for phase II trials based on exact tests with actual error rates by trading-off their nominal levels of significance and power. British Journal of Cancer. 2012 Nov; 107(1 1): 1801.

23. Alfirevic Z, Kelly AJ, Dowswell T. Intravenous oxytocin alone for cervical ripening and induction of labour. Cochrane Database of Systematic Reviews. 2009(4).

24. Mahendru R, Yadav S. Shortening the induction delivery interval with prostaglandins: a randomized controlled trial of solo or in combination. Journal of the Turkish German Gynecological Association. 2011;12(2):80.

cc) (i) Open Access This article is licensed under a Creative Commons Attribution 4.0 International License, which permits use, sharing, adaptation, distribution and reproduction in any medium or format, as long as you give appropriate credit to the original author(s) and the source, provide a link to the Creative Commons license, and indicate if changes were made. The images or other third party material in this article are included in the article's Creative Commons license, unless indicated otherwise in a credit line to the material. If material is not included in the article's Creative Commons license and your intended use is not permitted by statutory regulation or exceeds the permitted use, you will need to obtain permission directly from the copyright holder. To view a copy of this license, visit http://creativecommons.org/licenses/ by/4.0/. 